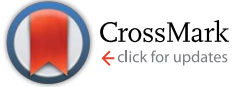

Cite this: RSC Adv., 2017, 7, 10454

Received 24th November 2016 Accepted 31st January 2017

DOI: $10.1039 / \mathrm{c} 6 \mathrm{ra} 27282 \mathrm{~g}$

rsc.li/rsc-advances

\title{
Coupling of anhydro-aldose tosylhydrazones with hydroxy compounds and carboxylic acids: a new route for the synthesis of $C-\beta$-D-glycopyranosylmethyl ethers and esters $\dagger$
}

\author{
Tímea Kaszás, Marietta Tóth, Sándor Kun and László Somsák* \\ Cross couplings of $O$-peracylated 2,6-anhydro-aldose tosylhydrazones ( $C$-( $\beta$-D-glycopyranosyl) \\ formaldehyde tosylhydrazones) with alcohols, phenols, and carboxylic acids were studied under \\ thermic or photolytic conditions in the presence of $\mathrm{K}_{3} \mathrm{PO}_{4}$ or $\mathrm{LiOtBu}$. The reactions failed with $\mathrm{EtOH}$, \\ $\mathrm{BnOH}$, or $\mathrm{tBuOH}$, however, $\left(\mathrm{CF}_{3}\right)_{2} \mathrm{CHOH}$, electron poor phenols and carboxylic acids gave the \\ corresponding $C$ - $\beta$-D-glycopyranosylmethyl ethers and esters, respectively, representing a new access \\ to these glycomimetic compounds.
}

\section{Introduction}

Metal-catalysed and metal-free cross coupling reactions have profoundly changed the way how complex organic molecules are assembled nowadays. ${ }^{1}$ Metal-free coupling reactions can be a good choice to avoid the use of expensive and toxic metals and ligands. In the last decade tosylhydrazones emerged as reactants in both metal-catalysed and uncatalysed coupling reactions $^{2-4}$ for example with alcohols and phenols, ${ }^{5,6}$ carboxylic acids, ${ }^{7,8}$ amines, ${ }^{\mathbf{9 - 1 1}}$ thiols, ${ }^{\mathbf{1 2 - 1 4}}$ arylboronic acids, ${ }^{15}$ aryl triflates, ${ }^{16}$ aryl halides, ${ }^{17}$ and benzyl halides. ${ }^{18}$

Despite the use of a large variety of aliphatic and aromatic tosylhydrazones in cross couplings, analogous reactions with anhydro-aldose tosylhydrazones have not yet been investigated. While tosylhydrazones can easily be obtained from aldehydes or ketones, anhydro-aldose tosylhydrazones are not readily available, and their preparation needs special methods. Thus, the reduction of glycosyl cyanides by RANEY®-nickel in the presence of $\mathrm{NaH}_{2} \mathrm{PO}_{2}$ with in situ trapping of the intermediate imine with tosylhydrazine yields anhydro-aldose tosylhydrazones. ${ }^{19-21}$ Synthetic utility of these compounds as carbene precursors was also examined to result in exo-glycals in aprotic Bamford-Stevens-reactions. ${ }^{20,22,23}$

Insertion of carbenes into $\mathrm{O}-\mathrm{H}$ bonds is a long known transformation. ${ }^{24}$ Carbenes generated from tosylhydrazones were inserted into alcohols and phenols ${ }^{5,6,25-30}$ as well as into carboxylic acids ${ }^{7,8}$ to give the corresponding ethers and esters, respectively.

Department of Organic Chemistry, University of Debrecen, PO Box 400, H-4002 Debrecen, Hungary. E-mail: somsak.laszlo@science.unideb.hu; Fax: +36 52512744; Tel: +3652512900 ext. 22348

$\dagger$ Electronic supplementary information (ESI) available. See DOI: 10.1039/c6ra27282g
Only a few methods can be found in the literature for the synthesis of $C$-glycopyranosylmethyl ether and ester derivatives G (Scheme 1). Such compounds are most frequently prepared by etherification/esterification of $C$-glycopyranosyl methanols $\mathbf{F}$ obtained by ozonolysis-reduction reaction sequences (routes $a$ and $b$ ) from $C$ - $\alpha$-D-glycopyranosyl allenes $\mathbf{B},{ }^{31,32} C$-glycopyranosyl ethenes $\mathbf{C}$ of both $\alpha-\mathrm{D}^{33,34}$ and $\beta$-D ${ }^{35}$ configurations, reduction of methyl ( $C$ - $\beta$-D-glycopyranosyl) formate $\mathbf{D}$ (route $c$ ), ${ }^{36}$ or ring opening of glycal epoxides $\mathbf{E}$ by the Grignard-reagent (iPrO) $\mathrm{Me}_{2} \mathrm{SiCH}_{2} \mathrm{MgCl}$ followed by Tamao-Kumada oxidation (route $d$ ) to give $\beta$-D-configured $C$-glycopyranosyl methanol derivatives G. $^{37}$ By using this methodology, ether-linked glycoside mimics were synthesized from bioactive compounds such as ezetimibe ${ }^{38}$ and $4^{\prime}$-demethylepipodophyllotoxin ${ }^{39}$ derivatives. $C$ - $\beta$-D-Glycopyranosyl siloxymethanes $\mathbf{H}$ were obtained from variously protected 1-Oacetates of mono and disaccharides in $\mathrm{Co}_{2}(\mathrm{CO})_{8}$ catalyzed reactions with hydrosilane in the presence of carbon monoxide (route $e$ ). ${ }^{\mathbf{4 0}-\mathbf{4 4}}$ Replacement of the siloxy moiety by an acetoxy group furnished $C$ - $\beta$-D-glycopyranosylmethyl acetates ${ }^{\mathbf{4 0 , 4 3}} \mathbf{G}$ and such compounds were also prepared by nucleophilic substitution of epimeric mixtures of $C$-D-glycopyranosylmethyl iodides $\mathrm{I}$ by $n \mathrm{Bu}_{4} \mathrm{NOAc}$ (route $f$ ). ${ }^{45}$ Scheme 1 allows one to estimate the number of synthetic steps necessary to get the target compounds $\mathbf{G}$ from a common precursor, a suitably protected 1-O-acetyl glycose derivative A.

Given the above interest in $C$-glycopyranosylmethyl ethers and esters $\mathbf{G}$ we envisaged that cross coupling reactions of anhydro-aldose tosylhydrazones $\mathbf{J}$ (easily obtained from glycosyl cyanides $\mathbf{K}$ on route $g$ ) with alcohols, phenols or carboxylic acids may directly lead to these types of glycomimetics. Herein we disclose our trials in this field which can provide new, alternative, and shorter reaction pathways to the above compounds, 


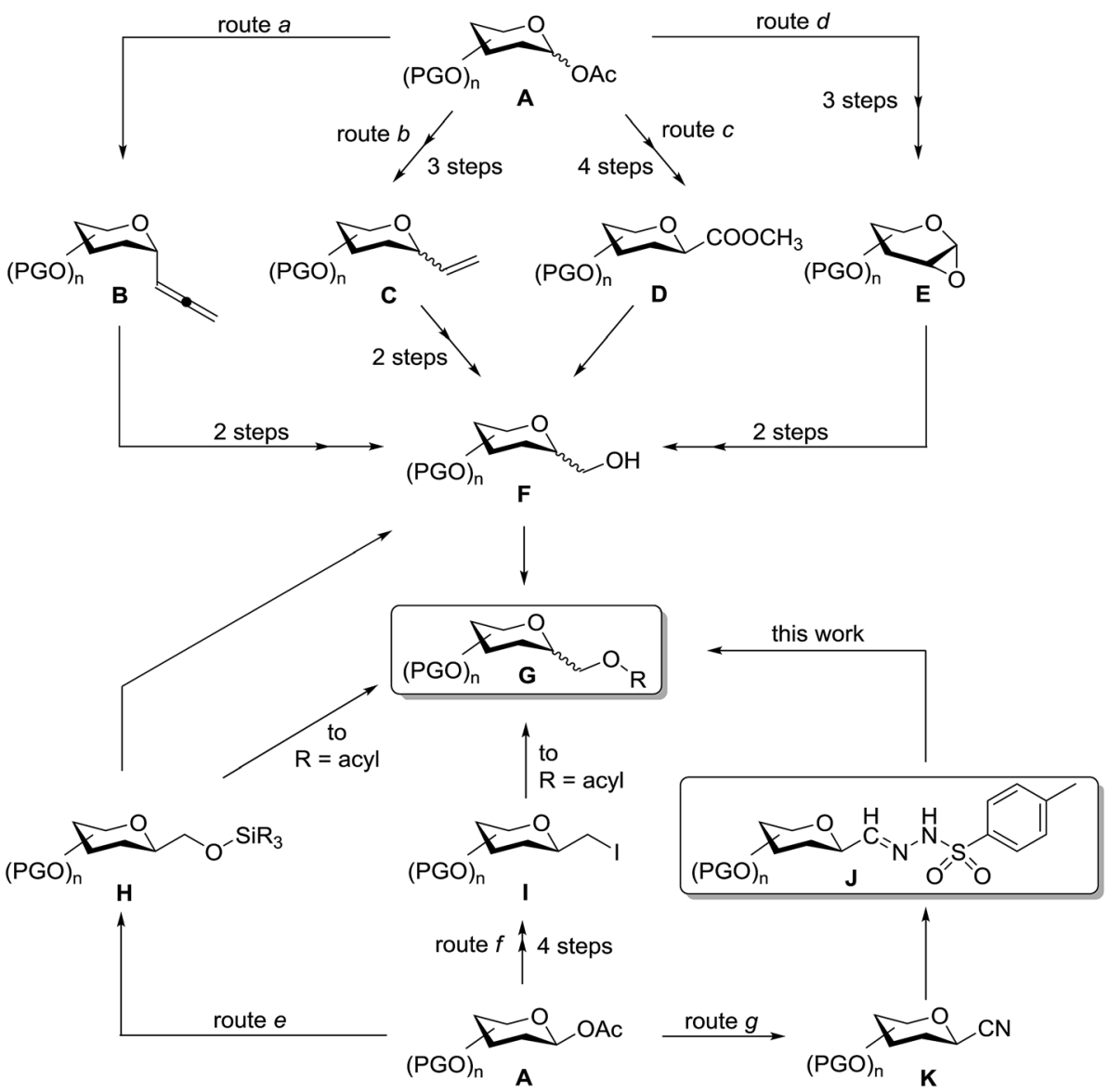

Scheme 1 Synthetic routes toward C-glycosylmethyl ethers and esters.

Table 1 Test of solvents and bases for the generation of $C$-glucosylmethylene carbene

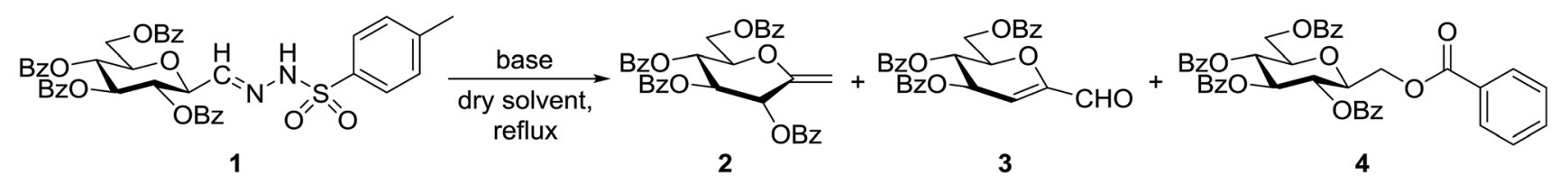

\begin{tabular}{|c|c|c|c|c|c|}
\hline \multirow[b]{2}{*}{ Entry } & \multirow[b]{2}{*}{ Solvent } & \multirow[b]{2}{*}{ Base (equiv.) } & \multicolumn{3}{|c|}{ Yield $^{a}(\%)$} \\
\hline & & & 2 & 3 & 4 \\
\hline 1 & 1,4-Dioxane & $\mathrm{NaH}(10)$ & $72^{b}$ & - & - \\
\hline 2 & 1,4-Dioxane & $\mathrm{K}_{2} \mathrm{CO}_{3}(1.5)$ & 21 & 5 & 16 \\
\hline 3 & 1,4-Dioxane & $\mathrm{K}_{2} \mathrm{CO}_{3}(5)$ & 26 & 6 & 9 \\
\hline 4 & 1,4-Dioxane & $\mathrm{K}_{2} \mathrm{CO}_{3}(10)$ & 25 & 9 & 5 \\
\hline 5 & 1,4-Dioxane & $\mathrm{LiO} t \mathrm{Bu}(5)$ & 24 & - & - \\
\hline 6 & 1,4-Dioxane & LiOtBu (5) & $50^{c}$ & - & - \\
\hline 7 & 1,4-Dioxane & $\mathrm{Bu}_{4} \mathrm{NF}(5)$ & $44^{c}$ & + & 14 \\
\hline 8 & 1,4-Dioxane & $\mathrm{K}_{3} \mathrm{PO}_{4}(3)$ & 46 & - & - \\
\hline 9 & 1,4-Dioxane & $\mathrm{K}_{3} \mathrm{PO}_{4}(5)$ & 70 & - & - \\
\hline 10 & $\mathrm{PhF}$ & $\mathrm{K}_{3} \mathrm{PO}_{4}(5)$ & 10 & - & - \\
\hline 11 & $\mathrm{PhF}$ & $\mathrm{K}_{3} \mathrm{PO}_{4}(5)$ & $29^{d}$ & - & - \\
\hline
\end{tabular}

${ }^{a}$ Isolated yields from a complex mixture which do not reflect the actual product ratios. ${ }^{b}$ Literature experiment. ${ }^{20,21} c$ Performed in a sealed tube, reaction temp. $110{ }^{\circ} \mathrm{C} .{ }^{d}$ Performed in a sealed tube, reaction temp. $100{ }^{\circ} \mathrm{C}$. 


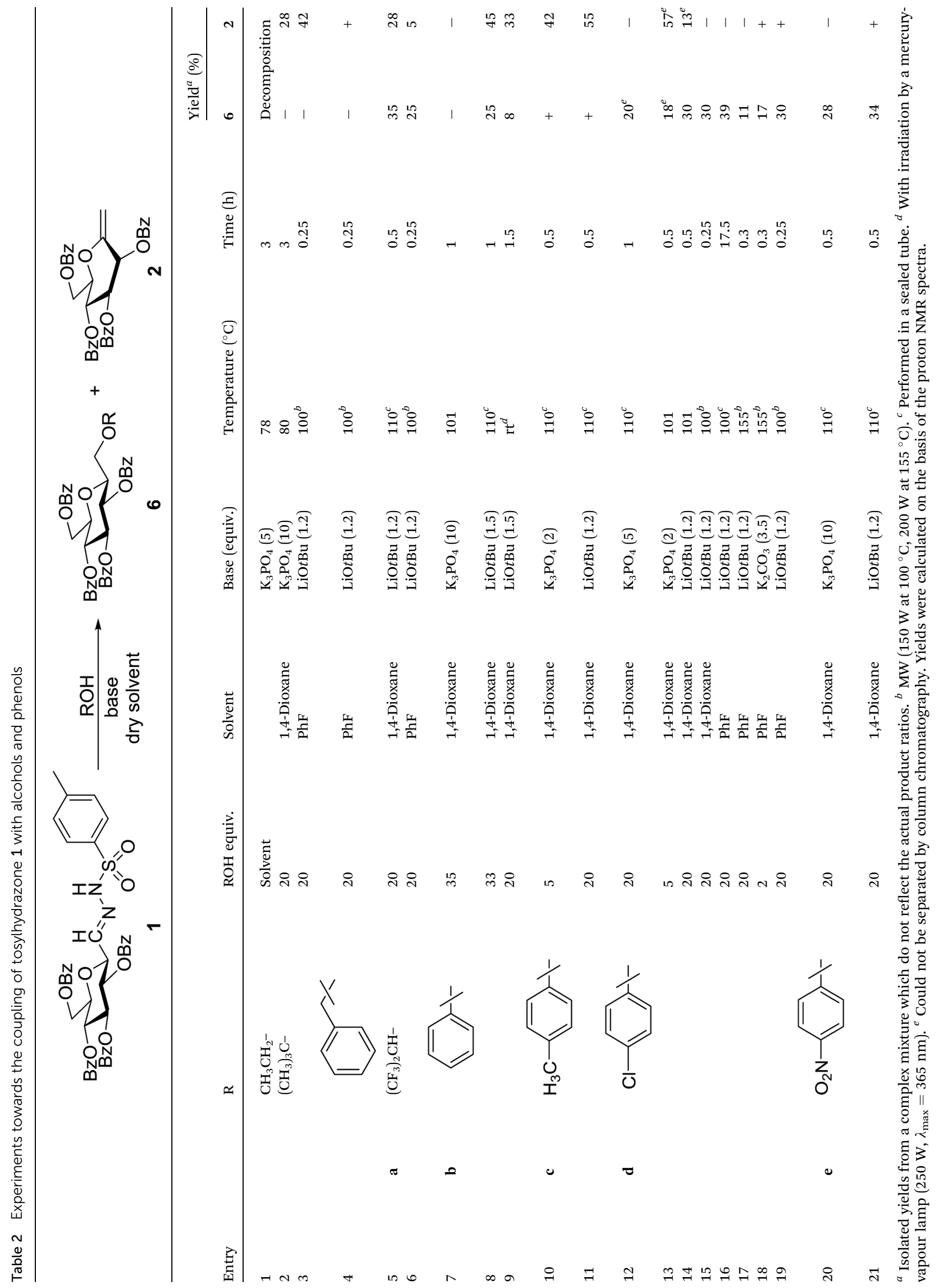


and also represent the first cross couplings with anhydro-aldose tosylhydrazones.

\section{Results and discussion}

In our previous studies, ${ }^{20,21}$ carbene generation from anhydroaldose tosylhydrazones was effected by using $\mathrm{NaH}$ (Table 1 , entry 1). To find more easily operable bases several salts were screened with $O$-perbenzoylated 2,6-anhydro-D-glycero-D-guloheptose tosylhydrazone: ( $C$-( $\beta$-D-glucopyranosyl)formaldehyde tosylhydrazone $)^{20,21}(\mathbf{1})$ in the absence of any trapping agent to give the corresponding exo-glucal 2. The bases $\mathrm{K}_{2} \mathrm{CO}_{3}$, $\mathrm{LiO} t \mathrm{Bu}$, and $\mathrm{Bu}_{4} \mathrm{NF}$ were not efficient enough for the reaction (Table 1 , entries 2-7) since the yields of 2 were low and/or 2 was accompanied by side-products such as 3 and $\mathbf{4}$. The formation of 3 can be explained by hydrolysis of the tosylhydrazone moiety due to traces of water in the reaction mixtures followed by elimination of benzoic acid from the 1-2 positions. The liberated benzoic acid may be a partner in an insertion reaction of the carbene ${ }^{35}$ derived from 1 to give benzoate ester 4 . On the other hand, the use of $\mathrm{K}_{3} \mathrm{PO}_{4}$ resulted in 2 as the only product in acceptable yield (entry 8), and its application in a 5-fold excess (entry 9) proved equipotent with the use of $\mathrm{NaH}$ (entry 1). In coupling reactions of tosylhydrazones with $\mathrm{OH}$-compounds fluorobenzene was reported to be an efficient solvent, ${ }^{6}$ however, in the above reactions it did not perform better but even worse than 1,4-dioxane (entries 10 and 11). Therefore, in the further transformations mainly $\mathrm{K}_{3} \mathrm{PO}_{4}$ and in some cases $\mathrm{LiO} t \mathrm{Bu}$ in 1,4-dioxane were employed as the base.

Tosylhydrazone 1, when reacted with EtOH as the solvent at reflux temperature in the presence of $\mathrm{K}_{3} \mathrm{PO}_{4}$ (5 equiv.), led only to decomposition whereupon no discrete product could be isolated from the reaction mixture (Table 2, entry 1). Similar experiments with $t \mathrm{BuOH}$ (either 20 equiv. in 1,4dioxane shown in entry 2 or as the solvent, 10 equiv. of $\mathrm{K}_{3} \mathrm{PO}_{4}$ ) allowed exo-glucal 2 or ester 4 to be isolated in less than $30 \%$ yields, respectively. In order to avoid the possibility of failure or incompleteness of the deprotonation of $\mathbf{1}$, its Li-salt $\mathbf{5}$ was prepared (Scheme 2), and subjected to carbene generation in the presence of both EtOH or $t \mathrm{BuOH}$ (neat or 100-160 equiv. in 1,4-dioxane under irradiation by a $250 \mathrm{~W}$ mercury-vapour lamp at $\lambda_{\max }=365 \mathrm{~nm}$ at $\mathrm{rt}$ or under thermic conditions at reflux temperature), however, only decomposition or traces of $\mathbf{2}$ or $\mathbf{4}$ could be detected in these reaction mixtures. To check the effect of $\mathrm{PhF}^{6}$ the reactions of 1 with $t \mathrm{BuOH}$ or $\mathrm{BnOH}$ (both 20 equiv., entries 3 and 4, respectively) in the presence of LiOtBu (1.2 equiv.) were carried out in this solvent under MW heating, however, only the formation of 2 could be observed.

From the reaction of 1 with $\left(\mathrm{CF}_{3}\right)_{2} \mathrm{CHOH}$ in the presence of $\mathrm{LiO} t \mathrm{Bu}$ the coupled product 6a could be isolated beside some exo-glucal 2 (Table 2, entries 5 and 6). The use of $\mathrm{PhF}$ as the

\$ This is the systematic name according to IUPAC carbohydrate nomenclature, however, the one in parenthesis reflects the parent sugar configuration in a more easily followable way, therefore, both names will be applied throughout this text.

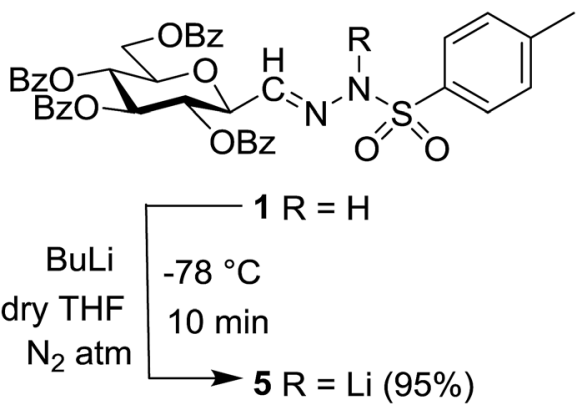

Scheme 2 Formation of Li-salt 5 from anhydro-aldose tosylhydrazone 1.

solvent (entry 6) was inferior to 1,4-dioxane (entry 5) in these reactions, as well.

Next, we turned to analogous transformations with phenols (Table 2). Reaction of 1 with phenol gave a complex mixture in the presence of $\mathrm{K}_{3} \mathrm{PO}_{4}$ (Table 2, entry 7), but resulted in ether $\mathbf{6 b}$ in moderate and low yields with $\mathrm{LiO} t \mathrm{Bu}$ under thermic or photolytic conditions, respectively (entries 8 and 9). From the reaction of $p$-cresol (entries 10 and 11) exo-glucal 2 was isolated as the main product regardless of base. However, transformations with $p$-chloro- (entries 12-15) and $p$-nitro-phenol (entries 20 and 21) provided the desired ethers $6 \mathbf{d}$ and $6 \mathbf{6}$, respectively, in moderate yields both with $\mathrm{K}_{3} \mathrm{PO}_{4}$ and $\mathrm{LiO} t \mathrm{Bu}$. In the case of $p$-chloro-phenol $\mathrm{PhF}$ was again tried as the solvent (entries 16-19) with both bases and under conventional or MW heating, however, only a slight increase of the yield was observed with oil bath heating in a sealed tube (entry 15).

Coupling reactions of anhydro-aldose tosylhydrazones with carboxylic acids in the presence of $\mathrm{K}_{3} \mathrm{PO}_{4}$ were also examined (Table 3). Reactions with aliphatic carboxylic acids resulted in the desired esters $7 \mathbf{a}-\mathbf{e}$ as the sole products with moderate and good yields (Table 3, entries 1-6). Coupling reactions with benzoic, 2-naphtoic, and substituted benzoic acids gave compounds $\mathbf{7 f - 1}$, respectively, in moderate yields (entries 7-15). Application of higher excess of carboxylic acids and the base generally increased the yields (compare entries $3-4,9-10)$. Adapting the applied reaction conditions to sugar derived carboxylic acids $\left(O\right.$-peracetylated D-galactonic acid ${ }^{46}$ $O$-perbenzoylated $C$-( $\beta$-D-glucopyranosyl)formic acid, ${ }^{47} O$-peracetylated $C$-( $\beta$-D-galactopyranosyl)formic acid, ${ }^{48}$ 1,2-O-isopropylidene-3,5-O-benzylidene-D-glucofuranuronic acid $^{49}$ ) the expected $\mathbf{7 m}-\mathbf{m}$, respectively, were isolated in good yields (entries 16-19).

The examinations were extended to the D-galacto configured tosylhydrazone 8 (Table 4). The corresponding esters 9ac derived from aliphatic carboxylic acids were isolated in moderate yields (entries 1-3), while 9d was obtained from $O$-perbenzoylated $C$-( $\beta$-D-glucopyranosyl)formic acid in good yield (entry 4).

A comparison of the investigated reactions allows one to conclude that the acidity of the OH-bond of the coupling partners seems to be essential in terms of the yields (Table 5). While alcohols (entries 1-3), and the electron rich (and thereby less acidic) $p$-cresol (entry 4) did not give the expected ethers, 
Table 3 Reactions of tosylhydrazone 1 with carboxylic acids

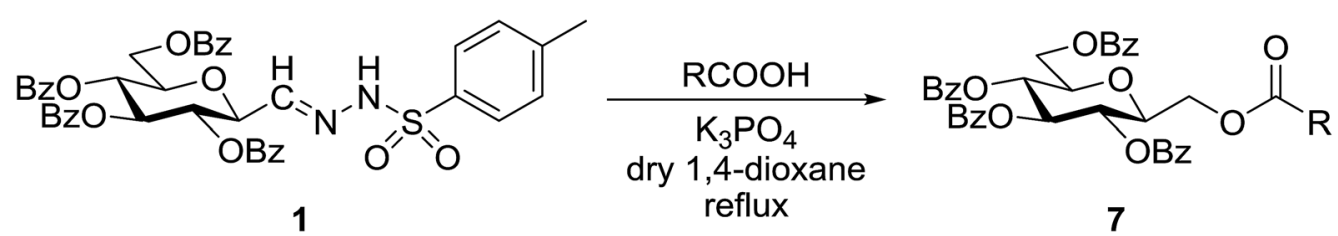

\begin{tabular}{|c|c|c|c|c|c|}
\hline & & & & & Yield (\%) \\
\hline Entry & & $\mathrm{R}$ & RCOOH equiv. & $\mathrm{K}_{3} \mathrm{PO}_{4}$ equiv. & 7 \\
\hline 1 & $\mathbf{a}$ & $\mathrm{CH}_{3}-$ & 20 & 10 & 31 \\
\hline 2 & b & $\mathrm{CH}_{3} \mathrm{CH}_{2-}$ & 20 & 10 & 49 \\
\hline 3 & c & & 2 & 2 & 39 \\
\hline 4 & & & 20 & 10 & 58 \\
\hline 5 & d & & 5 & 5 & 39 \\
\hline 6 & e & & 5 & 5 & 28 \\
\hline 7 & $\mathbf{f}^{a}$ & & 40 & 20 & 22 \\
\hline 8 & $\mathrm{~g}$ & & 20 & 10 & 37 \\
\hline 9 & $\mathbf{h}$ & & 5 & 7 & 23 \\
\hline 10 & & & 20 & 20 & 43 \\
\hline 11 & $\mathrm{i}$ & $\mathrm{H}_{3}$ & 20 & 25 & 29 \\
\hline 12 & $\mathbf{j}$ & & 5 & 9 & 33 \\
\hline 13 & & & 20 & 25 & 51 \\
\hline 14 & $\mathbf{k}$ & & 3 & 8 & 36 \\
\hline 15 & 1 & & 20 & 15 & 51 \\
\hline 16 & $\mathbf{m}$ & & 5 & 5 & 48 \\
\hline 17 & $\mathbf{n}$ & & 5 & 4 & 60 \\
\hline
\end{tabular}




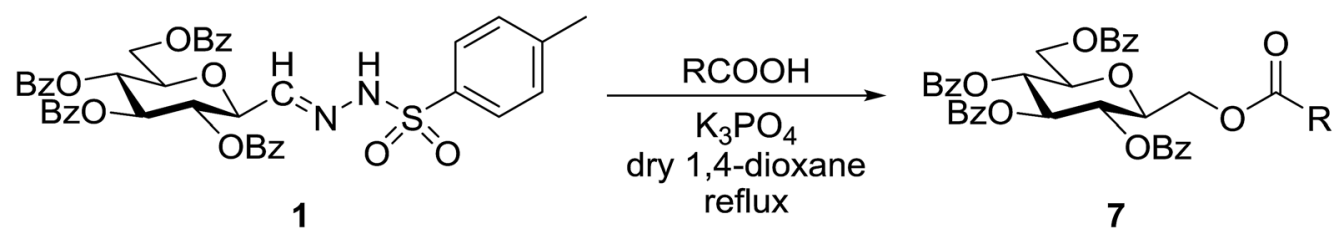

Entry

Table 4 Coupling of tosylhydrazone 8 with carboxylic acids

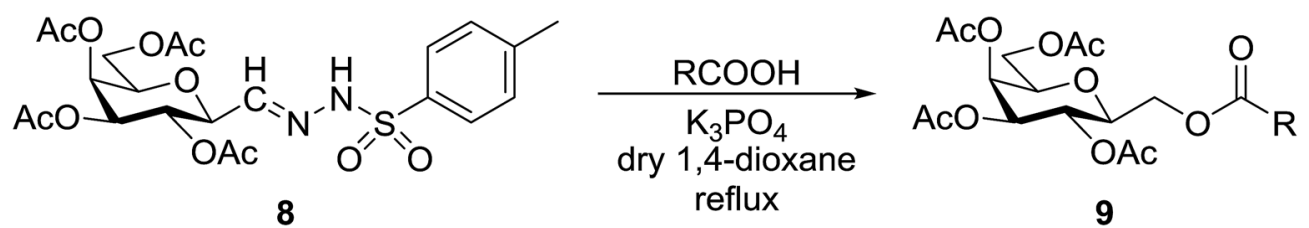

\begin{tabular}{|c|c|c|c|c|c|}
\hline \multirow[b]{2}{*}{ Entry } & & \multirow[b]{2}{*}{$\mathrm{R}$} & \multirow[b]{2}{*}{$\mathrm{RCOOH}$ equiv. } & \multirow[b]{2}{*}{$\mathrm{K}_{3} \mathrm{PO}_{4}$ equiv. } & \multirow{2}{*}{$\frac{\text { Yield }(\%)}{9}$} \\
\hline & & & & & \\
\hline 1 & a & $\mathrm{CH}_{3}-$ & 20 & 10 & 51 \\
\hline 2 & b & $\mathrm{CH}_{3} \mathrm{CH}_{2}-$ & 5 & 4 & 30 \\
\hline 3 & c & & 2 & 2 & 25 \\
\hline 4 & d & & 5 & 3 & 75 \\
\hline
\end{tabular}

phenol, $p$-Cl- and $p$ - $\mathrm{NO}_{2}$-phenols of higher acidity (entries 5, 6, and 8) as well as carboxylic acids (entries 9-24) gave the expected coupling products. This assumption is supported by the reaction of $\mathbf{1}$ with hexafluoro-isopropanol (entry 7) which also gave the expected coupled product. It is noteworthy that 4hydroxybenzoic acid (entry 12) reacted only at the $\mathrm{COOH}$ group, a finding also corroborating the role of acidity of the coupling partner. Interestingly, sugar derived carboxylic acids (entries 21-24) gave the highest yield of the products. Based on these experiences, it can be assumed that from the possible mechanistic pathways ${ }^{25}$ (Scheme 3) protonation of either the intermediate diazo compound (path a) or the carbene (path $b$ ) is 
Table 5 Comparison of the acidity $\left(p K_{a}\right)$ of the investigated alcohols, phenols and carboxylic acids and its influence on the yields

\begin{tabular}{llllr}
\hline Entry & Reagent & Reagent equiv. & Yield of the coupled product & $\mathrm{p} K_{\mathrm{a}}$ \\
\hline 1 & $\left(\mathrm{CH}_{3}\right)_{3} \mathrm{COH}$ & 20 & None & 17.0 \\
2 & $\mathrm{CH}_{3} \mathrm{CH}_{2} \mathrm{OH}$ & 20 & None & 51 \\
& & & 50
\end{tabular}<smiles>OCc1ccccc1</smiles>

4

5

6

7

8

9

10

11

12

13

14

15

16

17<smiles>O=C(O)CCCC[C@@H]1CCSS1</smiles><smiles>O=C(O)c1ccc(O)cc1</smiles><smiles>COc1ccc(C(=O)O)cc1</smiles><smiles>O=C(O)Cc1ccccc1</smiles><smiles>O=C(O)c1ccccc1</smiles><smiles>O=C(O)c1ccc2ccccc2c1</smiles><smiles>O=C(O)CNC(=O)c1ccccc1</smiles>

18<smiles>O=C(O)c1ccc([N+](=O)[O-])cc1</smiles><smiles>Nc1ccc(C(=O)O)cc1</smiles>

20
20

20

20

20

20

20

20

20

20 (with 1)

5 (with 8)

20 (with 1)

20 (with 8)

20

20

20 (with 1)
2 (with 8)

5

20

3

20

$\mathrm{COOH}$
None

None

Trace

$25(6 b)$

39 (6d)

35 (6a)

$34(6 e)$

49 (7b)

30 (9b)

31 (7a)

51 (9a)

39 (7d)

$4.8^{a}$

$43(7 h)$

4.6

50

29 (7i)

4.5

50

58 (7c)

25 (9c)

$22(7 \mathbf{f})$

4.2

50

$37(7 g)$

4.2

50

$28(7 e)$

3.6

50

$51(7 \mathbf{j})$

3.4

50

$36(7 \mathbf{k})$

2.5

50<smiles>Nc1ccccc1C(=O)O</smiles>

$51(71)$

2.2

50 
Table 5 (Contd.)

Entry

\footnotetext{
${ }^{a}$ Taken from SciFinder (https://scifinder.cas.org/scifinder/view/scifinder/scifinderExplore.jsf) predicted properties calculated using Advanced Chemistry Development (ACD/Labs) Software V11.02 (๔ 1994-2017 ACD/Labs). ${ }^{b}$ The predicted data were in the given range.
}

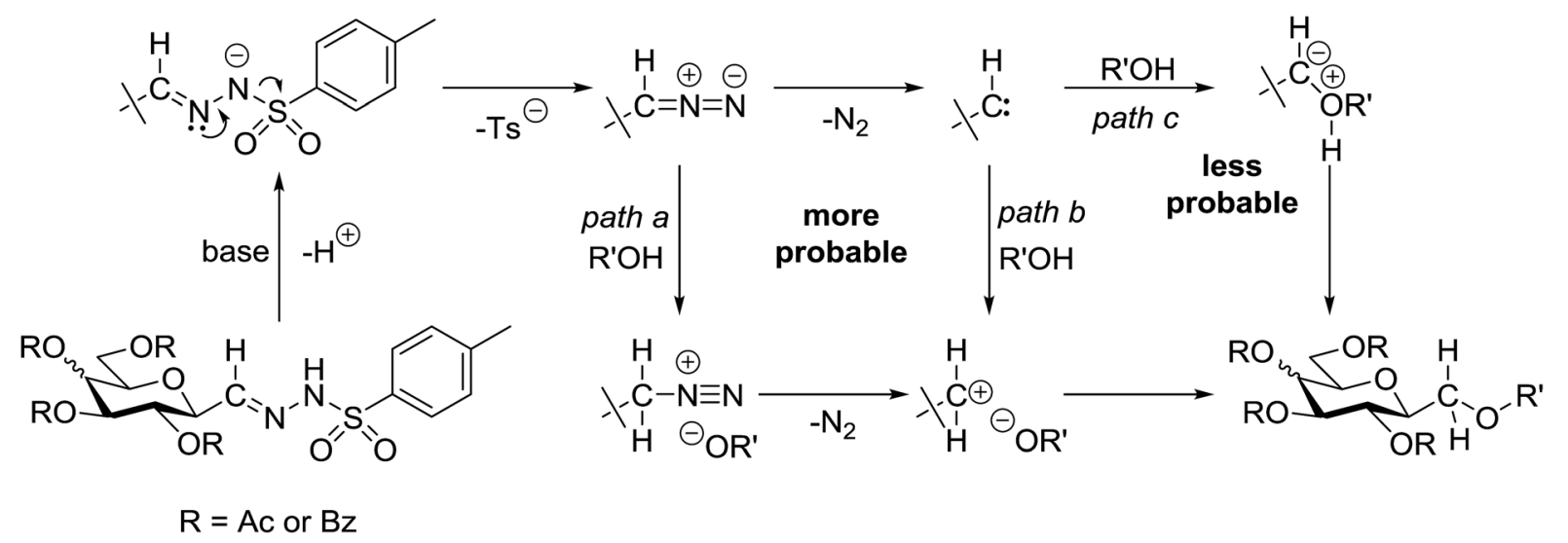

Scheme 3 Mechanistic possibilities of the transformations.

more probable than the direct insertion of the carbene in the $\mathrm{OH}$ bond (path c).

\section{Conclusion}

This study on the coupling reactions of $C$-( $\beta$-D-glycopyranosyl $)$ formaldehyde (2,6-anhydro-aldose) tosylhydrazones with $\mathrm{OH}$ compounds revealed that perfluoroalkanols, electron poor phenols and carboxylic acids gave moderate to good yields of the expected glycopyranosylmethyl ethers and esters, respectively, while normal alcohols and electron rich phenols furnished no coupled products. The method seems especially suitable to form glycopyranosylmethyl esters of sugar derived carboxylic acids, thereby opening a new possibility to get such kinds of disaccharide mimetics. In addition, the scope of tolerable functionalities in tosylhydrazone couplings was also extended to amino, carboxamide, and disulfide groups.

\section{Acknowledgements}

This work was supported by the Hungarian Scientific Research Fund (OTKA 109450), by the European Union and the State of Hungary, co-financed by the European Social Fund in the framework of TÁMOP-4.2.4.A/2-11/1-2012-0001 'National 
Excellence Program' (to MT) and by the University of Debrecen (5N5XBTDDTOMA320).

\section{References}

1 Metal-Catalyzed Cross-Coupling Reactions, ed. A. de Meijere and F. Diederich, Wiley-VCH, 2004.

2 J. Barluenga and C. Valdés, Angew. Chem., Int. Ed., 2011, 50, 7486-7500.

3 Z. Shao and H. Zhang, Chem. Soc. Rev., 2012, 41, 560-572.

4 Q. Xiao, Y. Zhang and J. B. Wang, Acc. Chem. Res., 2013, 46, 236-247.

5 S. Chandrasekhar, G. Rajaiah, L. Chandraiah and D. N. Swamy, Synlett, 2001, 2001, 1779-1780.

6 J. Barluenga, M. Tomás-Gamasa, F. Aznar and C. Valdés, Angew. Chem., Int. Ed., 2010, 49, 4993-4996.

7 A.-H. García-Muñoz, M. Tomás-Gamasa, M. C. Pérez-Aguilar, E. Cuevas-Yañez and C. Valdés, Eur. J. Org. Chem., 2012, 3925-3928.

8 A. Zhou, L. Wu, D. Li, Q. Chen, X. Zhang and W. Xia, Chin. J. Chem., 2012, 30, 1862-1866.

9 A. Hamze, B. Tréguier, J.-D. Brion and M. Alami, Org. Biomol. Chem., 2011, 9, 6200-6204.

10 A. Khanna, C. Maung, K. R. Johnson, T. T. Luong and D. L. Van Vranken, Org. Lett., 2012, 14, 3233-3235.

11 J. Aziz, J.-D. Brion, A. Hamze and M. Alami, Adv. Synth. Catal., 2013, 355, 2417-2429.

12 Q. Ding, B. Cao, J. Yuan, X. Liu and Y. Peng, Org. Biomol. Chem., 2011, 9, 748-751.

13 Q. Ding, X. Liu, J. Yu, Q. Zhang, D. Wang, B. Cao and Y. Peng, Tetrahedron, 2012, 68, 3937-3941.

14 Y. Lin, P. Luo, Q. Zheng, Y. Liu, X. Sang and Q. Ding, RSC Adv., 2014, 4, 16855-16863.

15 X. Zhao, J. Jing, K. Lu, Y. Zhang and J. B. Wang, Chem. Commun., 2010, 1724-1726.

16 B. Tréguier, A. Hamze, O. Provot, J.-D. Brion and M. Alami, Tetrahedron Lett., 2009, 50, 6549-6552.

17 J. Barluenga, P. Moriel, C. Valdés and F. Aznar, Angew. Chem., Int. Ed., 2007, 46, 5587-5590.

18 Q. Xiao, J. Ma, Y. Yang, Y. Zhang and J. B. Wang, Org. Lett., 2009, 11, 4732-4735.

19 M. Tóth and L. Somsák, Tetrahedron Lett., 2001, 42, 2723-2725.

20 M. Tóth, K. E. Kövér, A. Bényei and L. Somsák, Org. Biomol. Chem., 2003, 1, 4039-4046.

21 M. Tóth, L. Somsák and D. Goyard, Preparation of 2,6Anhydro-Aldose Tosylhydrazones in Carbohydrate Chemistry: Proven Synthetic Methods, ed. P. Kováč, CRC Press, Boca Raton, 2012, vol. 1, pp. 355-365.

22 M. Tóth and L. Somsák, J. Chem. Soc., Perkin Trans. 1, 2001, 942-943.

23 M. Tóth, S. Kun, L. Somsák and D. Goyard, Preparation of ExoGlycals from (C-Glycopyranosyl)formaldehyde Tosylhydrazones in Carbohydrate Chemistry: Proven Synthetic Methods, ed. P. Kováč, CRC Press, Boca Raton, 2012, vol. 1, pp. 367-375.

24 M. Regitz, Methoden der organischen Chemie (Houben-Weyl), Thieme, Stuttgart, 1989. vol. E19b.
25 R. Grandi, A. Marchesini, U. M. Pagnoni and R. Trave, J. Org. Chem., 1976, 41, 1755-1758.

26 W. Kirmse, K. Kund, E. Ritzer, A. E. Dorigo and K. N. Houk, J. Am. Chem. Soc., 1986, 108, 6045-6046.

27 X. Creary, M. E. Mehrsheikh-Mohammadi and S. McDonald, J. Org. Chem., 1987, 52, 3254-3263.

28 G. Hoemberger, A. E. Dorigo, W. Kirmse and K. N. Houk, J. Am. Chem. Soc., 1989, 111, 475-477.

29 W. Kirmse and K. Kund, J. Am. Chem. Soc., 1989, 111, 14651473.

30 W. Kirmse and K. Kund, J. Org. Chem., 1990, 55, 2325-2332. 31 L. Kröger, D. Henkensmeier, A. Schäfer and J. Thiem, Bioorg. Med. Chem. Lett., 2004, 14, 73-75.

32 M. I. Torres-Sanchez, C. Zaccaria, B. Buzzi, G. Miglio, G. Lombardi, L. Polito, G. Russo and L. Lay, Chem.-Eur. J., 2007, 13, 6623-6635.

33 D. Zhai, W. Zhai and R. M. Williams, J. Am. Chem. Soc., 1988, 110, 2501-2505.

34 R. Chang, T.-T. Vo and N. S. Finney, Carbohydr. Res., 2006, 341, 1998-2004.

35 C. Mayato, R. L. Dorta and J. T. Vázquez, Tetrahedron: Asymmetry, 2007, 18, 931-948.

36 K. C. Nicolaou, H. Flörke, M. G. Egan, T. Barth and V. A. Estevez, Tetrahedron Lett., 1995, 36, 1775-1778.

37 F. P. Boulineau and A. Wei, J. Org. Chem., 2004, 69, 33913399.

38 M. Werder, H. Hauser and E. M. Carreira, J. Med. Chem., 2005, 48, 6035-6053.

39 P. Allevi, M. Anastasia, P. Ciuffreda and A. Scala, J. Carbohydr. Chem., 1993, 12, 209-222.

40 N. Chatani, T. Ikeda, T. Sano, N. Sonoda, H. Kurosawa, Y. Kawasaki and S. Murai, J. Org. Chem., 1988, 53, 3387-3389.

41 S. J. Spak and O. R. Martin, Tetrahedron, 2000, 56, 217-224.

42 D. C. Croll and L. R. Schroeder, J. Wood Chem. Technol., 2005, 24, 27-38.

43 Y. Li, Z. Yin, B. Wang, X.-B. Meng and Z.-J. Li, Tetrahedron, 2012, 68, 6981-6989.

44 W. Yao, M.-J. Xia, X.-B. Meng, Q. Li and Z.-J. Li, Org. Biomol. Chem., 2014, 12, 8180-8195.

45 S. Toumieux, P. Compain and O. R. Martin, Tetrahedron Lett., 2005, 46, 4731-4735.

46 C. D. Hurd and J. C. Sowden, J. Am. Chem. Soc., 1938, 60, 235237.

47 K. Czifrák, P. Szilágyi and L. Somsák, Tetrahedron: Asymmetry, 2005, 16, 127-141.

48 R. W. Myers and Y. C. Lee, Carbohydr. Res., 1986, 152, 143158.

49 L. Zervas and P. Sessler, Ber. Dtsch. Chem. Ges., 1933, 66, 1326-1329.

50 Dissociation Constants Of Organic Acids And Bases, http:// sites.chem.colostate.edu/diverdi/all_courses/CRC\%20reference\%20data/dissociation\%20constants\%20of\%20organic\%20acids\%20and\%20bases.pdf, accessed January 12017.

51 D. H. Ripin and D. A. Evans, $\mathrm{p} K_{\mathrm{a}}{ }^{\prime} \mathrm{s}$ of Inorganic and Oxo-Acids, http://evans.rc.fas.harvard.edu/pdf/evans_pKa_ table.pdf, accessed January 12017. 